\title{
The Image of Women as Reflected in Somali Proverbs: A Feminist Analysis in the Case of Shinile Zone
}

\author{
Kahsay Chekole \\ Jijiga University College of social Science and Humanities, Department of English Language and Literature)
}

\begin{abstract}
The general aim of the study was to investigate the portrayal of women in Somali proverbs in feminist perspective. The analysis focused on the images that are attached to women in proverbs. What positions are women given in social, cultural, and in other social affairs? How are women imaged in proverbs? What kind of patriarchal beliefs do proverbs narrated about women reflect?

Having identified the potential informants through snowball and purposive sampling techniques, data was collected through unstructured interview and focus group discussion. Then, the collected data was translated from original language (Somali) into English using communicative means of translation. Based on the information gained from the informants, the proverbs were categorized into recurring themes. Selected proverbs were arranged for analysis based in their recurring themes. In the analysis and interpretations of the proverbs, attention had been given to the feminist theoretical approach and the context in which these proverbs can be created so as to show how the proverbs portray the realities of the women under study.

The findings of this study illustrate that both negative and positive attitude of Ethiopian Somali people towards women. Despite this fact, the proverbs of the Ethiopian Somali (Shinile zone) are unbalanced in that women are portrayed positively and in complementary role only in a few proverbs. Most proverbs indicated that women are evil, dangerous, unfaithful or morally loose, unreliable, untrustworthy, thus, intellectually inferior. The implication is that men usually use these stereotypes as grounds to legitimize their authority over women.

The proverbs further showed the senselessness of women's thought and actions. This simply showed the society's misconception about women. In other instances, though very few, women are represented positively and in complementary terms, these proverbs tend to serve the interests of men as they sustain or reinforce the traditional gender stereotype. For instance, representing a woman as "the boss of home because she is multi-task and able to feed her family, or as "heart of the house" because she has borne children, is not a complement but one way of attempting women to continue the good work which means men should continue to enjoy such patriarchal stereotypes as being the boss of the home who cannot consult the wife on important the relationship between husband and wife matters.

Thus, Contrary to men, Women are portrayed positively only in a very few proverbs. Most proverbs indicated that women are dependent, evil, lazy and inferior in both self-esteem and intelligence. The implication is that men usually use these stereotypes as grounds to legitimize their authority over women. Some of the proverbs further showed that the senselessness of women's thought and actions. This is simply showed the societies' misconception about women.

The finding of the study also indicated that the inferiority of women in Ethiopian Somali proverbs culture and male-female relationship in community. This study has tried to show that the proverbs of womanhood in Ethiopian Somali proverbs reveal an attempt that denigrating and disempowering woman. It seems that such negatively constructed cultural law and proverbs constantly used in the society the negative image and uncomfortable space to woman are unfortunately made permanent. Most of the Ethiopian Somali (shinlle zone) proverbs are saying depend on the behaviors of women. The societies were portrayed women as inferior of men. As reflected in the proverbs, the behaviors of women are considered as bad, unconfident, unreliable, unfaithful and so on. Hence, Women are negatively perceived by men dominated Ethiopian Somali community particularly in Shinile Zone.
\end{abstract}

DOI: $10.7176 / \mathrm{JLLL} / 61-01$

Publication date:October $31^{\text {st }} 2019$

\section{CHAPTER ONE}

Introduction

\subsection{Background of the Study}

Jeylan (2009) argued that proverbs in general should not be taken as signs of wisdom. Some proverbs especially in Africa have been used to maintain gendered life through conveying the African people's understanding of masculinity and feminist. Such sexist proverbs are created to reinforce male superiority. Thereby, women are victims of proverb-based discriminations and always are convinced that they are worthless, unproductive and inferior. Furthermore, Dundes (1987) confirmed that folk idea or worldview as expressed through folklore, particularly through proverb, has its negative side regarding ethnic, sex, minority and national stereotypes.

Tyson (2006) also support this idea that women are portrayed as decisive in traditional gender roles or 
patriarchal ideologies. As Tyson stated in her text entitled Critical Theory of Today, woman who has internalized the norms and values of patriarchy, which can be defined, in short, as any culture that privileges men by promoting traditional gender roles. Traditional gender roles cast men as rational, strong, protective, and decisive; they cast women as emotional (irrational), weak, nurturing, and submissive.

These gender roles According to Tyson(2006) have been used very successfully to justify inequities, which still occur today, such as excluding women from equal access to leadership and decision-making positions (in the family as well as in politics, academia, and the corporate world). According to Tyson (2006) Women are oppressed by patriarchy economically, politically, socially, and psychologically; patriarchal ideology is the primary means by which they are kept so. She also added that in every domain where patriarchy reigns, woman is other: she is objectified and marginalized. Consequently, Feminist criticism examines the ways in which literature (and other cultural productions) reinforces or undermines the economic, political, social, and psychological oppression of women in literary criticism (folklore elements).

\subsection{Statement of the Problem}

According to Boswell (1962,) folklore is one of the essential aspects of peoples' way of life. It is an important people's customs, traditions and institutions. In preliterate society, it serves as the storehouse of culture and history. Consequently, Boswel (1962) stresses that studying folklore can strongly serve as a means of studying the people it belong to. Moreover, Dorson (1972) emphasizes that by closely examining folklore elements, it is possible to learn the social, political, cultural as well as economic realities of a society. Hence, Proverbs are elements of folklore and they constitute a cultural heritage, which is hand down to us by the past generations.

According to Abrahams (1982), proverbs criticize moral problems either by directing future actions or by altering a point of view towards something that has already happened. In many African cultures a feeling for language, for imagery and for the expression of abstract ideas through compressed and allusive phraseology comes out particularly in proverbs (Finnegan, 1970). As to Mieder (2004), African proverbs are common ways of expressing religious ideas and feelings. "It is in proverbs they find the remains of the oldest forms of African religion and philosophical wisdom." The Ibo people of Nigeria view them as the palm-oil with which words are eaten and the horse on which the conversation rides.

In the same way, Ethiopia is a country with a long history of writing. Even though literacy is still far from universal, storytelling remains important in many parts of the country. In support of this idea, Melakneh (2001) stated that, the study of folklore in Ethiopia seems to be a recent development. Melakneh emphasizes that although the attempt to collect Ethiopian oral tradition can be traced to when the missionaries appeared in the country, the participation of Ethiopians in the folklore had been limited until the second half of the twentieth century.

Although there are studies on proverbs in some ethnic groups of Ethiopia, for instance Mesfin (2014) on Kafa proverbs and Fikre (2012) on Wolayta proverbs, and Tadesse (2004) on Guji-Oromo proverbs; as to the knowledge of the investigators no research has been conducted on the Ethiopian Somali proverbs specifically on the on the image of women in Ethiopian proverbs in feminist perspective.

Thus, in this study, we attempted to identify and analyze the image of women as depicted in Ethiopian Somali oral literature particularly in their proverbs. . For the purpose of this report, oral literature has been taken as the form of literature that is very much dependent on verbal performance for its dissemination. Oral literature genres act as very important vehicles through which the attitudes and beliefs of a people are expressed. The images used in oral literature can therefore be used to reveal a great deal about the attitudes of a society. Oral literature is a crucial tool in shaping social life and the Ethiopian Somali people like in any other communities have their own oral literatures through which they express their culture, custom and belief. Therefore, study intends to answer the following research question questions:

1. How are women imaged in proverbs?

2. What kind of patriarchal beliefs do proverbs narrated about women reflect?

3. do women portrayed negatively or positively as reflected in the proverbs?

\subsection{Objectives of the study}

The general aim of the study is to investigate the portrayal of women in Somali proverbs from feministic perspective. The study intends to analyze proverbs in order to examine the extent in which the society expects women to conduct themselves in order to be acceptable by society. Therefore, the study will focus on the following specific objectives

$\checkmark$ To examine how women are portrayed in proverbs

$\checkmark$ To assert whether women are oppressed by the patriarchal ideology in proverbs

$\checkmark$ To show the position that women are given in different socio-economic affairs ias reflected proverbs

$\checkmark$ To identify patriarchal created beliefs in proverbs that reveal cultural stereotypes of the society with regards to women. 


\subsection{Significance of the study}

Studying image of women in Ethiopian Somali is significance for firstly it reveals how women are imaged in Ethiopian Somali proverbs. In other ways, it will mirror whether they are imaged positively or negatively. It also reflects the social, economic and psychological make of women. It can also serve as a dimension of knowledge about social and cultural images of women in general and proverb in particular. It wills also shades light on Ethiopian Somali people's traditional values, customs and other beliefs expressed in the proverbs. In addition, the study will be significant for other researchers and scholars of literature with the information about the social, economic political other affairs of women and may help them as springboard for further study in Ethiopian Somali literature and folklore.

\subsection{Delimitation and scope of the study}

A given society inevitably possesses variety of oral traditions such as folksong, folktales, proverbs riddles, poems and others which are used in different occasions for different purposes However, folklore in general and oral tradition in particular is a broader field of study. As result, the study focuses on proverbs which are one classification oral tradition.

The scope study is limited into "Shinile Zone" one of the nine administrative zones of Ethiopian Somali National Regional State. Aamong the nine administrative clusters, Shine zone is purposely sampled due to accessibility and security conveniences. Thus, it is visible that the image of women as reflected in Ethiopian Somali proverbs from can be conducted on traditional livestock and human healing practices in various parts of Shinile zone in Somali regional state.

\subsection{Theoretical Approach of the study}

The study of folklore can be approached from different perspectives. Consequently, there are different contemporary theories concerning the study of folklore. According to Finnegan, (1991) different approaches to the study of folklore includes; comparative, historical constructional, feminism, ideological and contextual, cross cultural mass cultural and functionalism. Furthermore, Finnegan (1992) sates that oral literature or verbal arts are considered form of literature "they can be approached through any perhaps all of the established methods of literary analysis."

Feminism is seen to embrace all endeavors, made towards highlighting the recognition of the systematic discrimination against women on grounds of gender and a commitment to work towards change (Tsikata, 1991). According to the foregoing definition, scholars as well as other actives who involve themselves in women's issues are invariably since they are committed to changing the prevailing gender disparities that have often proved oppressive towards women.

In literature, feminist literary scholarship basically performs two major roles. In the first place, feminist literary artist have to write about being a woman and describe reality from a woman's point of view.

Secondly, it also looks at how women are portrayed in many literary texts; women have been portrayed in ways restricted by conventional stereotypes. Women are widely represented as objects to be discussed, exchanged and evaluated by men in such representations women are regularly attributed particular sorts of character (silly, trivial, domestic). Feminist criticism contests such representation. In doing so, it challenges men on the ways in which they choose to see and think of women; investigates recurrent images or symbols through which women are represented, and promotes new kinds of alternative images. In such works, feminist criticism is concerned with women as content of literature. This aspect forms the crux of this study. The way women are portrayed forms the subject of our concern in this research.

In societies where images of women are largely voyeuristic stereotypes, the implied address of images of women in a male construct. Normally women are perceived as passive audience and have to adopt such ways of appreciating these "male stream" literary works which accept these dominant construct of ideal and norms. As a radical correction, feminist criticism analyses the different system of address available in literary works addressed to women and investigates new forms of address to be directed more appropriately at mixed gender readership/audience ship. In doing so, feminist analysis is concerned with women as implied audience.

In the analysis the image of women in Somali proverbs, the study borrowed this principle to determine how women have come up with new forms of address to reassure their images in proverbs In addition to feminist approach, the study of folklore requires the social context in which certain performance is carried out. Thus, contextual approach to folklore will also apply for it will helps to textual analysis of proverbs from feminist perspective. This theoretical approach is also influenced by folklorists in which they emphasis the function of folklore elements in a given society. In relation to this, Dorson $(1972,20)$ sates that contextual approach is concerned with "the role played by folklore in given culture." furthermore, Dorson(1972) indicates that the question at the heart of this approach is "how does folklore function in culture of given society 


\section{CHAPTER TWO}

\section{METHODOLOGY}

An analysis of the image of women is central in feminist research. Feminist research to a large extent relies on qualitative method. The essence of a qualitative research is to discover the meaning and assumption underlying human behavior (Mayan, M 1996). This study used a qualitative paradigm that enabled it to fully understand the image of women as reflected in Somali proverbs

\subsection{Research instruments}

The study used interviews and focus group discussion which are primary method data collection. The interview was held with the key informants and they were interviewed about the image of women given in proverbs, the stereotypical ideologies given women in proverbs. Weather there is a patriarchal thinking that is given to women, why they use such proverbs, the issues raised in the proverbs. The interview was carried out at the informants' home and village.

In addition to interview and observation, the researchers used focus group discussion to collect data for this study. Focus group discussion is useful to cross check, validate the data and to avoid bias. We employed focus group discussion to get the information that cannot be collected through interview and to discuss the thematic issues of the proverbs with informants how they portray women. Through group discussion, it enabled the researchers to learn on the thematic issue and the words which are ambiguous and unclear to researcher.

\subsection{Transcription, Translation and Analysis of the study}

In pursuing the objective of the study, data comprising fifty Ethiopian Somali proverbs relating to womanhood were collected. The data was collected between May and July 2016. Since proverb usage and interpretation are context-sensitive, the collection was restricted to situations in which the proverbs were actually used by Somali language speakers.

After the data was collected, all the data gathered through tape recording were transcribed to written form immediately after the collection was over. On some tapes the whole information were transcribed. On the other tapes, only the required elements are transcribed and written in Somali language on note pads together with the description of the context and the names of the subjects. The transcribed data was translated into English. As the proverbs originate from the cultural elements, most of them are laden with cultural words which have no equivalent terms in English. For such expressions, the translation gave a providing the description of the terms by including the term in the translated version of the proverbs. Then, the collected proverbs were translated. Most of the proverbs seem to originate from cultural elements. In the same way, they seem to emerge from the perception of a resemblance between two phenomena, which of course, creates a meaningful image that brings about emotive effect. Therefore, the majority of them are metaphorical.

The appropriate approach to translation for metaphorical and cultural texts, as Newmark (1982) ascertains, is communicative translation. The communicative approach to translation seeks to make a translated text communicable to a reader. It gives a chance for a translator to make the text smoother, lighter, and easier to understand. The translator tries in the target language to write a little better than the original and to make the text more communicable.

According to Newmark (1982: 50), "The approach gives the translator the right to correct or improve the logic, to replace the clumsy words, to remove obscurities, to eliminate repetition, to exclude the less likely interpretations of ambiguity, and to clarify the highly cultural terms". In this approach, it is possible to remodel the syntax and use commoner collocations and more familiar words. Thus, Newmark indicates that the communicative approach to translation is a better way of translation for metaphorical texts. Similarly, he suggests that texts that are characterized by cultural elements and local jargons should be translated communicatively. When translating metaphorical texts, the translator can translate the text by metaphor using the same or similar image in the target language. Therefore, words in the target language don't lose their meanings in the original language.

Due to the above stated usage it, the communicative approach to translation has been employed for translation of proverbs in this thesis. The proverbs were translated from the original language (i.e. Somali language) into the target language (i.e. English) in a way that they give an image or tell something to the reader in English. In this way of translation, those texts, which are metaphorical in the original language, remain metaphorical in the target language. However, the researchers do not think that they avoided all problems in his translation of the proverbs. We admit that there could be losses of the poetic quality of the original texts since problems of translation of oral literature mainly of proverbs are common.

After the proverbs are being translated into English, they were closely examined and grouped into the basis of the theme in which they convey. Then the groups were further divided into classes based on their theme they convey. After carrying out the translation, the researchers embarked on the analysis. Finally, the data collected through the interview and FGD have s been clustered and analyzed under feminist analysis. 


\section{CHAPTER THREE}

\section{DATA ANALYSIS AND INTERPRETATION}

This chapter deals with the analysis of the Ethiopian Somali proverbs about women, how women are imaged in the proverbs and their relationships with men. The analysis discussed on the theme of proverbs related with the image of women. After collecting the proverbs from the community elders, the proverbs were classified according their themes they made. These include:

\subsection{Proverbs that portray the positive Images of Women}

A. Naagla'aani waa nafla'aan

If there is no woman there is no life

The proverb shows the communities' cultural and traditional positive image of women. The above proverb recognizes that man existence without women is worthless. The proverb indicated the Ethiopian Somali cultural perception and understanding that women play an important role in their family. The proverb literally translates that women are important and part of their society in strengthening their family and making life ever happiest in their community. It also strengthen women are part and parcel of life that they help their husband by sharing their won part. The above proverbs affirmed also women have a remarkable role in the life of their husbands..

\section{B. Haween la'aani waa hoy la'aan}

Where there are no women, there is no home

According the above proverb, no women mean shelter. Therefore, as they are the main pillars of the society then without them there is no means of joyful life. According to the informant' information, in Ethiopian Somali culture, women Men and women make different contributions to make life possible. Although the two sexes are spatially categorized to carry out culturally different roles, they are in a condition to supplement each other's responsibilities. The above proverbs portray women as very crucial sections of the family and society. Furthermore the proverb indicated that a man's life without a woman is extremely despairing. The proverb that says where there are no women, there is no home becomes applicable in this context.

Thus, the proverb tells us the importance of women in creating a receptive environment around home. In other words, it establishes social sub-structures and patterns of expectations for the women and glorifies women for the comfortable services they provide men and endorses men's entitlement to the services.

\section{Guri ann hooyo lahayni waa lama degaan}

A home without a mother is like a desert

This proverb states that according Ethiopian Somali culture women play an important role in making life happy and easier. The above proverb also shows that women make home trustworthy, happier and lovable. Moreover it states that life without women it is dark, fearful and very horrible. The proverb may also be used to state how women can involve and participate in social and economic, cultural, political affairs in male dominated society. In other sense, the proverb may be employed to suggest in a traditional male-dominated society, women contribute a great deal towards protecting the social and economic systems of their families.

\section{Nin rag ah haweentii ka adag, doqonna isgaa ka adag}

A good man may be controlled by his wife, while lesser man dominates his wife.

The above proverb indicates that women gender functioning is essential to strong family relationship and to continue life happily. Women's role in the family was described as the steppingstone of family life and central to preserve culture and tradition in the community. Furthermore, the above proverbs indicated that women play a valuable role in breaking patriarchal ideology in their community and private domain at their home.

Therefore, it shows Women's involvement in various spheres of cultural, social and economic is both central and vital. Thus, it tells the positive portrayal of women in the community and it may be described as essential realms of culture, which is essential in maintaining family and cohesive social relationships of women and men within the society. Generally, the above proverb states the communities' common beliefs that men get advice from their wives whenever they face critical problems.

E. Rag haween ayaa kala hor mariya

It's the women who make some men succeed where others fail

This proverb indicates the role of women in succeeding their husbands' achievement. In order to achieve you objective your wife should be there. Therefore, it indicates how women play in importance role in achieving their husband's success. It also tells us that men who have a wife can succeed while a man without woman fails. It seems that the proverb is recreated here to cater for the role of women in the society which demands that both men and women should be hard-working to provide food and drinking for their families. According to the informants, the burden is too heavy for only the husband to bear nowadays unlike as it was in the past when men were to be the sole bread winners of their families and when there was little or no socio-economic challenge. So, the proverb illustrates that women as well as men should work very hard to make happy their family and life of the society in general. 
F. Naag la'aani waa naf la'aan

To be without a woman is to be without life

The mentioned proverb indicates the crucial importance of a woman's support. The above proverbs indicated that women can serve as an advisor to their husbands. It also shows a common belief of the Ethiopian Somali community men can get advice from their wives whenever they face critical problems. Moreover, the above proverb portrays the positive image of women how they are part and parcel of their husband in providing crucial support and advice. It not only shows the positive portrayal of women in their community but also it gives lesson women are source of happiness and they make life complete and everlasting happy.

\section{G. Fuley habartii ma gablanto}

The mother of a coward does not lose her son

The joy of motherhood in Ethiopian Somali societies is often strengthened by the mother-child bond. The child is very dependent on the mother and by habit expects to receive (good things) from her. The image of the selfless love is described in the above proverb, which signifies motherhood as desirable, and thus addresses the fellowship face wants of woman as mother. The implied in the proverb is the belief that disturbances in motherchild bond results in the emotional, mental and physical suffering of the child. The proverb relates motherhood to life-enhancing and comforting quality and selflessness

In the mixed-sex verbal interaction in which the proverb was used (by the community to indicate the positive valuation of motherhood and which gives indirect message that one mother's scarification of love for her child. Both social and clinical psychologists have provided insights to the life enhancing quality of mothers for their children as emphasized in the proverb.

In other word, the proverb mentioned above shows that the tenderness and feelings of love between a mother and her child which starts usually long before the mother becomes pregnant, is everlasting. As the proverb also implies, the departure of a mother either by divorce or death usually victimizes her children since it causes the deprivation of their healthy and normal growth.

In this case, the positive image of motherhood becomes a mode of cognition and created positive recognition among society. The woman is also portrayed in the proverbs as being wise, or as somebody from whom one could learn lessons of life. In psychoanalytical terms, the proverb could be seen as indirectly evoking the maternal bond which, other psychoanalytically-orientated feminists have argued.

H. $\quad$ Awr awr wado iyo nin naagi waddo midna kaama leexdo.

You cannot escape the camel which is driven by another camel, nor the man who is driven by a woman.

The concept of the above proverb is that a woman skillfully uses a man for pursuing her issues. This proverb indicates that women are powerful and skilful for pursuing man. At it can be seen in the above, the proverb portrays the positive image of women that they are so artistic in persuading and pursuing man to themselves. The proverb also emphasizes that women are persuaders and they can make their own decision to convince others.

\subsection{Proverbs that portray women as unreliable and unpredictable}

\section{A. Cindhiga naageed iyo cir roobaad midna lama malayn karo.}

You never know what to expect from a woman and a cloudy sky

It is used to advise a husband to restrain his wife so that she may not become disobedient. The proverb may also be used to justify the belief of the community that women have no self-regulating autonomy and need the interference of men at all levels of decision-making in their life. The severity of the message in this proverb is increased if it is said to reform a husband who shared a common ground with his wife and decided to treat her as an equal partner. The main message of this proverb is that a woman is a person you cannot afford to trust at all. A woman is unpredictable, weak-brained and too easily overcome by emotion so that she acts irrationally even in the way that can be dangerous to the well-being of the home.

This justifies the man, as the ,head of the family, to arrive at certain crucial decisions that affect the whole family without the input of the wife. The proverb above highlights the Ethiopian Somali belief that a woman can never be trusted and if she knows your secrets, you will leave in fear for the whole of your life. This explains why the Ethiopian Somali people lay down the expectations of the various sexes.

As a result of his view about women, society tends to ignore them completely. They are neither consulted nor trusted even with issues which concern them such as control of their fertility and the number of children to have in the family. Women are expected to be passive consumers of male policies and decisions. Thus it shows that in Ethiopian Somali patriarchal dominated culture women are assumed as unreliable and unpredictable, a weaker, untrustworthy, and worthless beings.

Thus, it is important to examine the oral traditions of the Ethiopian Somali society as described in their proverbs women are considered as unpredictable. Knowing something in cloudy sky is so difficult and knowing what women are thinking is also difficult. So, it shows how women are portrayed negatively by the society in their culture and language. It also indicates how women are very secret and hidden in the culture and tradition of Ethiopian Somali people. In general the above described proverb explains the society's belief and custom that 
they portray women as difficult and dangerous to understand them.

\section{B. $\quad$ Kas dumar oo kadalloob rag kaaga dambeeyey kaad ku ogeyd ma aha.}

You do not know what is now in a woman's mind after she has been chatting with another man.

As reflected in the above proverbs, the behaviors of women are considered as bad, unconfident, unreliable, unfaithful and so on. Women are negatively sketched by patriarchal dominated Ethiopian Somali community. It seems that women are portrayed in the culture of the society as unfaithful and dishonest by the community. This shows the negative perception of the society towards women in their proverbs and traditions. The above mentioned proverb implies also women are more indecisive and unfaithfull as copmared to men. Thus, it is crtical to understant from the above proverb the Ethiopian somali society mispercive women as inferior and and unconfident tcompared to men.

C. Naagi nin ay taqaan nin ma mooddo.

A woman does not think of a man whom she knows well, as a man

This proverb describes the negative perception of the community towards women. As it is shown in the above proverb, women are portrayed as dishonest and disloyal. It seems that the proverbs used by the Ethiopian Somali people tactically obscuring the sex of the agent. But the fact that the affected is woman and the proverb user is male could be seen as presupposing man to be the agent.

On the other hand, why it is woman that is chosen as the disrespectful and irresponsible in the formulation of the proverb is that it is a way of making woman actually a sufferer in the culture. Man as speaker selects those elements of signification which, directly and indirectly, to portray women negatively. Thus, the selection of the woman to signify the irresponsible subject in proverb above depends on the presupposition that the community would be able to refer to the stereotypes of women assumed to be shared knowledge in the culture

D. Dumar wax uga xuni ma jiraan "ama tag, ama joog

There is nothing worse for a woman than either go or stay

The above mentioned proverb indicates that women canot make desision by themselves independently and effectively. The above proverb shows the communities perception of women as dependent and inferior than men. Futhermore, the above proverb shows women can not settle an issue by themselves in their society and they are wrongly percieved by the cummunity as dependen. It also states about the negatve image of women that the implication of this proverb is that, women are dependent on their husbands. This is to mean their future and stability depends on the success of their husbands.

What is more, the proverb implies that a woman must accept whatever an authority figures-most often husband order. Furthermore, the above proverb shows the society's misperception towards women they portray women as less powerful and decision makers. It also indicates the communities' exclusion of women from equal access to leadership and decision-making positions in the family as well as in politics, social, and the economics issues.

\section{E. $\quad$ Naago geel ka baxsaday nabastooday ka dayaan}

Women look for a lost camel in their bosom

The proverb presents the sexual vulnerability (helplessness or powerlessness) of women, which she fails to recognize to her own detriment due to her assumed weakness in reasoning. It is obvious in the narrative that woman is marked as different by virtue of her biological distinction, her possession of a bosom. This difference, in the patriarchal symbolic, suggests inferiority since the bosom or breast is considered powerless. The part bosom is gifted to whole, woman.

This psychological or biological gender difference has used by the proverb of Ethiopian Somali society to show the loss woman suffers due to her possession of breast or bosom for the lost animal (camel) and for the act of signifying her rejection of the relation of biological sex. Women's position therefore deconstructed the opposition between masculinity and feminity and necessarily challenges the very notion of identity.

Furthermore, the narrative of woman's sexual difference by the male speaker indicates insensitive construction of woman's subjective position and their position inferiority. Sex difference according to Ethiopian Somali culture and language for man thus signifies woman's defeat. This implys that women are illogical or highly unreasonable. Bossom is a women's chest or breast. So it means that women look for the lost camel in their breast which is totaly ssignifies the negative representation of women basedon their bilogicall diffrences.

F. $\quad$ Saqir naageed sirla'aan ma dhinto

Even if a woman dies in her childhood she will nevertheless have manage to swindle.

It is necessary to observe that the sex-biased proverbs themselves are too illogical to be even seen as cultural models of wisdom. The above Proverbs clearly faulty generalizations and could have originated as one man's illogical conclusions which other people, who also have gender prejudices, have come to accept as deceptions. If some women have been unreliable and unfaithful, to say that women are unreliable and unfaithful is the communities' misunderstanding of woman. The above proverb generalizes that women can not be clearly understood and it needs care to hundle them because they are difficult to undderstand their behavior. Thus, this proverb partrays that women are difficult and more mysterious to understand in wich they are imaged nagatively 
in Ethiopian somali proverbs.

\subsection{Proverbs that portray the bad behaviour of women}

A. Naag nin ay taqaah ninn ma moodo

If a woman knows a man very well, she might not consider him as a man.

The above proverb is explaines about bad behavior of women. According to the proverb relationship or knowing each other is nonsense for women. Proximity is not a sign of humanity for women. It considers women as selfish and none of social psychology. The society miss interpreted women through the proverb and does not believe by the equality of women and men. Women is not full super natural creature for them. They are half creature which compared to men.

B. Naago ama u samir, ama ka samir

Either sufer from women or suffer without them.

The proverb mentioned above telling us that it is not only the woman that can have a bad behavior only for her to blame her destiny for providing for her a bad husband, the man can have a good behavior towards the wife only to blame his destiny for giving a bad wife. The lesson inherent in the above proverb is that is no absolute good wife; one needs only to adjust to oneself so that men will be either suffer being with the women or prefers independent through divorce or separation. In this proverb, women are portrayed in the culture and customs of Ethiopian Somali society as having bad behavior while men are considered having good behavior in the proverb.

C. Naag waa balaayo loo baahan yahayo

A woman is necessary problem.

Different from the other proverbs here, a woman is portrayed as 'necessary problem'. It has amazing metaphorical expressions which undermine the personality of women. Even though, the community has an agreement on the necessity of women in their own life, they are also considering women as 'problem'. Nevertheless, this men dominate society has complex way of thinking towards their women.

D. Naag iyo karuurba sasabashaya laguwada

If you want to live with child and women, you will expect to have tolerance.

In this narrative proverb, the ability of woman to exercise her mental capacities is recognized. Here we find the behavior of women is comparing to child. This shows us that the behaviors of women are difficult and challengeable to understand them. It needs tolerance to manage their unwanted personality. They are not portrayed like self-confident person rather they are considering as a child. The communities' perception towards women is more patriarchal and indirectly supports the domination of men.

This is indeed noteworthy, especially as in the same in Ethiopian Somali culture; women are sometimes derogated as children who are incapable of independent thought. It seems, however, that this acknowledgement of the possession of wisdom, which is a promotion of competence face wants, derives from the cultural association of age with wisdom, and not only on the basis of intellectual empowerment of woman. Indeed in Ethiopian Somali culture and tradition, old women are accorded greater respect and granted more rights than younger women as described by the informants.

\section{E. Naag waa usmair ama ka Samir}

Have a patient for women or divorce her.

In their proverbial wisdom, Ethiopian Somali always perceive femininity as a primary symbol of faulty generating. They assume that that females are valueless and cannot think as male counterparts. In addition, they disvalue female's effort of accomplishing successful deeds. This is due to the prejudiced societal perception of females as always weaker than their male counterparts. Similarly, as their proverbial wisdom portray, Ethiopian Somali s do not give opportunity for females to make decisions. They believe that, females are incapable of making right decisions. As clearly indicated in the result section, they do not trust decisions made by females. They perceive females as individuals who always make wrong decisions in overall aspects of life.

As we see from the above proverb the behavior of women is portrayed as difficult and unmanageable. If somebody wants to live with them; first of all he expected to have patient. If it is not, he exposes himself to divorce. Therefore, the image of women in the society is not portrayed in a good manner. Always the society sketch women described as irrational and having variable behavior.

\subsection{Proverbs that Convey the Society's Perception of Women as less inferior and less Intelligent \\ A. Kal caano galeen kas ma galo}

Someone whose chest has milk will not have a mind.

In the above proverbs women are portrayed as less intelligent in their thinking ability. They are believed to think only in short terms. The above mentioned proverb conveys the society's bias against women's thought and practice. The proverb further illustrate that the brain of a woman is dull as compared to that of a man. The conception of the society towards women's knowledge is also reflected through the above proverb. 
Though Ethiopian Somali people belief reflects traditional patriarchal ideology in their proverbs towards women, there is no research finding that confirms the difference between the two sexes in their thinking and intelligent. Such kinds of proverbs discourage women from performing and achieving equal participation with women. This proverb indicates how women are portrayed as decisive and they are less powerful than man. In general, the above proverb sates women as unintelligent and not intellect.

B. Indheer-aragto rag waa ku yar tahay, naagana kuma jirto.

There are few intellectuals among men and there are none among women.

In the above proverb, women are considered as foolish in their thinking skills. Similarly, Jeylan (2009) argued that proverbs in general should not be taken as signs of wisdom. Some proverbs especially in Africa have been used to maintain gendered life through conveying the African people's understanding of masculinity and feminity. Such sexist proverbs are created to reinforce male superiority. Thereby, women are victims of proverbbased discriminations and always are convinced that they are worthless, unproductive and inferior. Therefore, the Ethiopian Somali considers women as none educative and intellectual. This kind of cultural belief of the society not only discourages women but also it can bring psychological oppression and pain of women.

C. Naag hill haa kasugin

Don't expect help from women.

Here, we can observe one of the Ethiopian Somali women behavior which believed by the community as a norm. For this patriarchal society woman has no perception of 'help'. 'Helping others' is the job of men. A woman is not expected to sketch in a good behavioral manner. The good and nice one is always gifted to men.

D. Naag waa guri ama god ha kaga jirto.

Your woman should be in the house or in the grave

The above proverb portrays the negative stereotypes of women. It indicates that women are perceived as less powerful than women in which they cannot participate in social and economic participation and involvement outside home. The proverb says women should be in the house or in the grave, this signifies how women are imaged negatively by the society. It seems that the Ethiopian Somali people cultural and patriarchal perception of women.

It implies also in the patriarchal of the dominated community, women are portrayed negatively. This proverb draws the clear social picture of weakness the society on femininity to allow participate in their social and economic involvements outside door or home. Those females who stay outdoors departing such the practical social situations are considered as prostitutes. As their long lived traditional practice and their biased orientation of gender polarity, Ethiopian Somali societies do not allow their female children or their wives to go outside at night or they allow them to go with males. As we can understand from the above proverb, it seems that the Ethiopian Somali community cast women as weak and irrational by promoting traditional and cultural thinking that women cannot participate in social economic affairs as .men counterparts.

E. Dumar hin ammaana leh

Women consider as a husband, who appreciates her.

Here a woman is portrayed as unconfident. The behavior of women is described through the ambition of appreciations. From the point of view of the proverb women always measured man by the extent of his appreciation. If somebody wants to be a husband he expected to give enormous appreciations to the women. As a result a woman is dependent on the word of men. Women are not self-confident. The community believed that women as dependent of men words. The socio cultural proverbs of Ethiopian Somali community are related to undermining women through different techniques. One of these techniques which mentioned in the above proverbs is dependent of women on the words of men. The society uses women inappropriately by designing the domination of men.

\subsection{Proverbs that conveys the communities' view of women as talkative, unfaithful and irrational}

A. Rag waa shaah, dumarna waa sheeko

Men like tea, women like conversation.

This proverb showed that, there are gender differences in controversial habits. The stereotype of chatty, talkative women is so prevalent that both literate and illiterate societies have long presumed that females speak more than men. This shows that women are the victims of malicious proverbs in a lot of languages. Therefore, it seems that women are disadvantaged by this proverbial expression but men are considers as silence and then consequently it leads that in order to be a good man, they should not talk. So this stereotype puts constraints on women and it should be dispelled unless it is founded scientifically.

B. $\quad$ Naag kun baa koodiso kow bay kala baxdaa.

Women talk with thousands of man but, finally she married one.

As we see from the above proverb, a woman is considered as talkative and undefined creature. She talked to thousands of men but finally she married one. May be those who talked to her was had an ambition to get her. Finally, she chooses one for her life. From this reason we cannot find the heart of women simply by considering 
her way of communication, because, they are wise and undefined creatures.

C. $\quad$ Naag abaal ho uqalin amah se haun diidinwaxba

Don't give a gift for women but borrowed her.

Here, women were portrayed as alienated to the gift. The communities were not believed by giving gift for women rather they had strong belief by borrowing something. This is all because of the personality of their women towards a gift. As we see from the proverb, the behavior of women is portrayed as bad and non-formal.

D. Waxaad taqaan guurso, waxaad taqaan ha kuu dhashee

Marry a woman you are sure of and you will have no doubt of your children

The import of this proverb is that a woman is a person you cannot afford to trust at all. According to the community' traditional perception, women are perceived as "unpredictable, weak-brained and too easily overcome by emotion so that she acts irrationally even in the way that can be dangerous to the well-being of the home. This justifies the man, as the honest and the leader of the family, to arrive at certain crucial decisions that affect the whole family without the input of the wife. The proverb above highlights the Ethiopian Somali belief that a woman can never be trusted and that you will leave in fear for the whole of your life.

As a result of their view about women, societies tend to ignore them completely. They are neither consulted nor trusted even with issues which concern them such as control of their fertility and the number of children to have in the family. Women are expected to be passive consumers of male policies and decisions. Nevertheless, events in our world today, particularly in Ethiopian Somali, show that the patriarchal view that women are a weaker, untrustworthy, and worthless.

\section{E. $\quad$ Naagjile iyo na xaris midna waxba kumalhan}

Women don't like good and smart man.

As human being good and smart men is interesting but, in the above proverbs women are not related to this reality. The interests of women were portrayed at the opposite direction of goodness and smartness. The society of Ethiopian Somali had an agreement on the ambition of aggressiveness for women.

F. Nagg been baa lausa xero galshaa runa waa lagn dhagaa

Cat cools women by false but, administers her by truth.

As reflected in the above proverbs women is objectifying as foolish. The role of women in Ethiopian Somali (shenille zone) is not comparable with men. As reflected in the proverb a woman is considered as object. They are not subject in any of their event. The administrator and cat cooler of women is always men. A man is always leader of women.

\subsection{Proverbs employed to teach men moral lessons about women}

The proverbs in this category form the mode since they have the highest number compared with the other groups. They are basically employed to teach men moral lessons about women by emphasizing some abnormal behavior which the Ethiopian Somali people think some women have. These proverbs are indirectly instructing men to move away from such women that have such bad social traits. The proverbs do not consider that it is possible for some men to have these traits being condemned in women

\section{A. Dumar iyo dheri toona yar yareysi malaha}

No little for women and pot.

As we observe from the above proverb women is compared with object. So a woman is not subject in this context. This proverb, similar to Proverb compares women with pot. It reflects the condition of women in Africa, a condition where they invest much of their energy and time on tedious and exhausting daily routines. In light of the productive and reproductive roles women play in Africa, there is nothing bad in the message of the current proverb simply because women are likened to pot in which they are described as object.

On the whole, the proverb encodes the irreverence held by the society towards women. The society uses the proverb to depict women in general as a group of people with inherent weakness, lacking wisdom, confidence, self assurance and good character. In this proverb, women as a group are simply criticized for failing "to follow the normative path laid out by the community. The debilitating effect of such portraiture is that women may internalize the negative attitudes held against them and convince themselves that they are really incapable of doing worthwhile things. They are considered as a 'pot'. In addition to this the theme of the proverb is completely inhuman. When we live in this world, through the way of our growth always age mattered. But according from the proverb this reality is absolutely violated. The concept 'No little for women ...' is far from our nature of humanity. Therefore the way of saying is the sign of women subordination in Ethiopian Somali community. On the other hand it is also shows the burden of women in the society.

B. Naag ningaawiyey kama gousata

Women didn't forget who knows her out of clothes.

As it can be seen in the above proverb, Women' sexual object is disempowered. This assumption is related to the representation of woman as being irresponsible and unconcerned with her own good. In the above proverb described, this irresponsibility is linked with love for vanity. The above proverb defines women as sex object. 
Women is portrayed as the addicted of sex.

The imagination and remembrance of women is measured by sex. According to the community perception women is explained as a commodity. Women is objectifying by men. Here the mental state of women is represented by practice of sex. The capacity of women thinking and performance is unfairly demarcated through sexuality. Ambition of sex is not only the gift of women. As a human being it is our common behavior. But in the opposite way the Ethiopian Somali community is characterize women as a pornographer. This shows us that how much the community is influencing women improperly.

C. Naagi naag lala qabo waa u col

The enemy of women is women.

As reflected in the proverb women are considered as enemy. Here women is comparing against women by enmity. For the community women have no peace each other. Even the enemy of women is not men rather it is women themselves. The Ethiopian Somali community believed that women are always in chaos, conflict and misunderstanding each other.

This patriarchal society repressed women through their proverbs. The socio cultural makeup of the society is believed by the domination of men. The women also believe these perceptions like their own life norms. Because the culture is men oriented. For the long period of time the Ethiopian Somali women is live through men dominated system. They have no equal right and acceptance in the society.

Generally, the images associated with women are a reflection of established societal patterns of behaviors expected of women. Women need to break away from the male stereotypic female roles. They need to fight traditional forces which have relegated them to an inferior and exploited position. Women need to question the structure and social relations that have facilitated their marginalization.

They need to find out how they acquired the negative stereotypic images which have been used to sideline them, leading them to occupy downtrodden status. Women constitute a force that can no longer be ignored, ridiculed or dismissed as negligible. In the light of the negative images, oral literature seems to be a coercive tool used by the community aimed at keeping women in subjugation.

\section{Chapter Four \\ Conclusion and Recommendation \\ a. Conclusion}

The present study sought to investigate Ethiopian Somali proverbs related to female stereotypes. The study attempted to explore how Ethiopian Somali women are portrayed in proverbs and saw whether proverbs discriminate against them or not. To attain the objectives set out in this study, we collected a number of proverbs from the informants in shinile zone that tackle women issues.

The findings of this study illustrate both negative and positive attitudes of Ethiopian Somali people towards women. Despite this fact, the proverbs of the Ethiopian Somali (Shinile zone) are unbalanced in that women are portrayed positively and in complementary role only in a few proverbs. Most proverbs indicated that women are evil, dangerous, unfaithful or morally loose, unreliable, untrustworthy, thus, intellectually inferior. The implication is that men usually use these stereotypes as grounds to legitimize their authority over women.

The proverbs further showed the senselessness of women's thought and actions. This simply showed the society's misconception about women. In other instances, though very few, women are represented positively and in complementary terms, these proverbs tend to serve the interests of men as they sustain or reinforce the traditional gender stereotype. For instance, representing a woman as "the boss of home because she is multi-task and able to feed her family, or as "heart of the house" because she has borne children, is not a complement but one way of attempting women to continue the good work which means men should continue to enjoy such patriarchal stereotypes as being the boss of the home who cannot consult the wife on important the relationship between husband and wife matters.

Thus, Contrary to men, Women are portrayed positively only in a very few proverbs. Most proverbs indicated that women are dependent, evil, lazy and inferior in both self-esteem and intelligence. The implication is that men usually use these stereotypes as grounds to legitimize their authority over women. Some of the proverbs further showed that the senselessness of women's thought and actions. This is simply showed the societies' misconception about women.

The inferiority of women in Ethiopian Somali proverbs can affect both the use of proverbs in the culture and male-female relationship in community. In the first place, sex-bias in the use of proverbs clearly undermines the integrity of the women as expressions of folk wisdom. For proverbs in the society to be worthy of the metaphorical description, they have to be humanely processed and used and this requires the interrogation of and opposition to the expression of gender bias.

This study has also tried to show the proverbs of women in Ethiopian Somali proverbs particularly in Shinile zone reveal an attempt at denigrating and disempowering woman. Apart from this, the encoding of a negative image of women in what is seen as an expression of the wisdom of the society has another disturbing 
significance. It seems to make such construction of negativism law, and as proverbs constantly used in the society the negative image and uncomfortable space allocated to woman are unfortunately made permanent.

Most of the Ethiopian Somali (shinlle zone) proverbs are saying depend on the behaviors of women. The societies portrayed women as inferior of men. As reflected in the proverbs, the behaviors of women are considered as bad, unconfident, unreliable, unfaithful and so on. Women are negatively sketched by men dominated Ethiopian Somali community.

Ethiopian Somali proverbs describe the inner thoughts, relationships, power structure and patterns of social control in the society. Thus, it is possible to note that Ethiopian Somali proverbs are reflectors of the thoughts, beliefs and socio-cultural values of the society.

\section{b. Recommendation}

The findings of this study indicated that women in Ethiopian Somali proverbs are culturally disadvantaged in their oral literature (proverbs). Hence, the researchers would like to address their suggestion to government officials particularly those who work in gender affairs to strive further in creating awareness in the society about gender equality. In doing so, they should vividly show cultural stereotypes that degrade women.

In the same manner, they should also teach the society about the roles that women could play in the socioeconomic and political affairs of the society. Specifically educational institutions have to enlighten the entire community that such type of oral traditions should not play any role other than providing historical significance. Although this study enabled us to discover that the image of women in Ethiopian Somali proverbs, there much still needs to be done in the area of Ethiopian Somali proverbs. We hope this research will inspire future scholars to look further into the rich Ethiopian Somali oral literature.

Therefore, we recommend that there should be further documentation and scholarly study of Ethiopian Somali oral literature in general and proverbs in particular. Scholars who intend to collect and study Ethiopian Somali proverbs can go to the communities so as to encounter live performances of Ethiopian oral literature at all the social occasions identified by the researchers.

As instigators, we are hoping that this study will be valuable to Ethiopian Somali readers in helping them gain a better understanding of and respect for their oral literature. Our advice to other scholars wishing to do study in Ethiopian Somali is to go to their hometowns or at least to communities whose customs they understand, and whose language they understand and can speak so that they will enjoy in studying and collecting their oral literature.

\section{References}

Abrahams, R. D., 1982. Proverbs and Proverbial Expressions, in Dorson, R. M. (Ed.). Folklore and Folklife: An Introduction. Chicago: University of Chicago Press. 117- 128. Available from: http://books.google.com/books [Accessed 20, February 2016].

Boswell, G .(1962.) Fundamental of Folk Literature..Oosterhout; Anthropological Published.

Chesania, (1994). Image of Women in Africa Literature. In Solomon Tsfaye (2012). Women's Image in Bench Folktales; A Thematic Analysis from Psych-Socia Feminist Perspective MA thesis BDU (unpublished).

Dorson ,R.(1972) Folklore and Folk Life ,An Introduction. London and Chicago: the University of Chicago Press. Dundes, A (1 965).The Study of Folklore. N.j. Prentice Hall Inc

Dundes, A. (1975). Analytic structure in folklore. The Hargue: Mountain

Fasiku, G. (2006). Yoruba proverbs, name and national consciousness. Journal of Pan African

Fikre A. (2012). An Analysis of Wolayta proverbs: Function in Focus: MA thesis, Addis Ababa University (Unpublished)

Finnegan, R. (1992). Oral Traditions and the Verbal Arts. Rutledge. A Guide to

Finnegan,R. (1970) African Oral Literature. New York; Oxford University press.

Jeylan, W. H. (2009). A discursive representation of women in sample proverbs from Ethiopia, Kenya and Sudan. Research in African Literature, 40, 96-107. Retrieved seb 17, 2015, from http:// muse: jhu.edu/journals/ral/summary/vo40.3.hussein.html.

Melakneh, Mengistu. (2005).The major themes and motifs of south Agaw folktales. MA thesis (Unpublished) Addis Ababa University; Ethiopia

Mieder, W. (2004). Proverb: A handbook. London: Greenwood press

Mesfin wedajo, (2012). Contents, Functions and Formal and Stylistic Features of Kafa

Tyson, L. (2006) critical theory Today: A User Friendly Guide. New York: Routledge. 